\title{
LEITORES EM DIFERENTES TEMPOS: A RECEPÇĀOO DO CONTO FELICIDADE CLANDESTINA, DE CLARICE LISPECTOR'
}

\section{READERS AT DIFFERENT TIMES: THE RECEPTION OF THE SHORT STORY FELICIDADE CLANDESTINA, BY CLARICE LISPECTOR}

\author{
Neide Luzia de Rezende ${ }^{2}$
}

RESUMO: O artigo trata da recepção de "Felicidade clandestina", de Clarice Lispector, considerando certas representações dos leitores especializados (professores e alunos de Letras, por exemplo) em diferentes épocas e circunstâncias que vêm sendo confrontadas pelos novos leitores (alunos da educação básica). As observações foram colhidas nas atividades docentes na Universidade de São Paulo, e o referencial teórico, além da fortuna crítica relativa ao conto, é composto pelos autores que tratam da Estética da Recepção, especialmente, Hans Robert Jauss e Wolfgang Iser, ao mesmo tempo em que se adota parte da interpretação do conto feita por Y. Rosenbaum (2006).

PALAVRAS-CHAVE: Recepção Estética. Leitora Ideal. Clarice Lispector. Felicidade Clandestina.

ABSTRACT: The article deals with the reception of "Felicidade clandestina", by Clarice Lispector, considering certain representations of specialized readers (teachers and students of Literature, for example) in different times and circumstances that have been confronted by new readers (students of basic education). The observations were collected in the teaching activities at the University of São Paulo and the theoretical framework in addition to the critical fortune related to the short story is composed of the authors who deal with the Aesthetics of Reception, especially Hans Robert Jauss and Wolfgang Iser, at the same time that I adopt part of the interpretation of the short story by $\mathrm{Y}$. Rosenbaum (2006).

KEYWORDS: Aesthetic reception. Ideal Reader. Clarice Lispector. Felicidade Clandestina.

${ }^{1}$ Artigo recebido em 15 de março e aceito em 30 de abril de 2021.

2 Professora de Metodologia de Ensino de Língua Portuguesa na Faculdade de Educação da Universidade de São Paulo; coordenadora do Grupo de Pesquisa Linguagens na Educação; integrante do GT Literatura e Ensino da ANPOLL. E-mail: neirez@usp. br. ORCID: https://orcid.org/0000-0001-7078-8727. 


\section{Introduçầo}

Assim como a literatura produzida é marcada pelos horizontes culturais de sua época, do mesmo modo a recepção estética o é, e esta se comunica de diferentes modos com as gerações futuras de leitores. No conto "Felicidade Clandestina", de Clarice Lispector, o desejo de uma menina na década de 30 pelo livro Reinações de Narizinho, de Monteiro Lobato, se tornou emblema de paixão pela leitura literária até hoje, desde que o livro de contos Felicidade clandestina foi publicado em 1971.

Cultivou-se na escola, a partir de então, mediante a presença constante do conto nos materiais didáticos, a imagem de uma leitora idealizada, que hoje não responde bem à apreensão da personagem feita pelos estudantes e tampouco inteiramente ao leitor implícito ${ }^{3}$ desse conto extraordinário.

Para a elaboração deste artigo são apresentadas fontes recentes, onde foram coletadas informações sobre a recepção do conto na escola, as quais permitiram trazer possibilidades de apreensão do texto a partir de uma perspectiva que leva em consideração questões sociais e culturais do leitor jovem contemporâneo, já que se trata de um conto que se abre para interpretação de leitores de diferentes temporalidades. Como afirma Yudith Rosenbaum:

Se o passado surge ressignificado pela consciência rememorante, também a leitura no presente acaba sendo mais um momento de reconstrução ficcional, pois é marca da modernidade na literatura a participação cada vez maior do leitor na significação da obra. (2006, p. 72).

Minha intenção é apreender aqui o(a) leitor(a) - em especial a leitora - que hoje lê o conto na escola com a mediação do(a) professor(a), por isso, ao mesmo tempo em que me refiro a(ao) aluna(o) também busco entender o(a) professor(a.) Para isso, fun-

\footnotetext{
${ }^{3}$ Segundo Iser, o leitor implícito "materializa o conjunto das pré-orientações que um texto ficcional oferece, como condições de recepção, a seus leitores possíveis. Em consequência, o leitor implícito não se funda em um substrato empírico, mas sim na estrutura do texto. Se daí inferimos que os textos só adquirem sua realidade ao serem lidos, isso significa que as condições de atualização do texto se inscrevem na própria construção do texto, que permitem constituir o sentido do texto na consciência receptiva do leitor. A concepção do leitor implícito designa então uma estrutura do texto que antecipa a presença do receptor." (ISER, 1996, v.2, p. 73).
} 
cionalizo duas dimensões do trabalho de pesquisa na área de educação: uma teórica e outra prática. A primeira se assenta na estética da recepção e na teoria do efeito literário, respectivamente desenvolvidas por Hans Robert Jauss e Wolfgang Iser em várias obras, principalmente em A história da literatura como provocação à teoria literária (JAUSS, 1994) e $O$ ato de leitura: uma teoria do efeito estético, v.1 e 2 (ISER, 1996).

No prefácio à segunda edição de seu livro, Iser observa que o conceito de estética da recepção precisa ser compreendido em duas dimensões distintas apesar da correspondência que mantêm; essa reciprocidade, que interessa aqui, coloca o leitor como instância da literatura. Jauss destaca o aspecto histórico e social da recepção e Iser lida com a dimensão textual e fenomenológica da recepção - "prefiguração da recepção" (ISER, 1996, p. 7). Do conto "Felicidade clandestina", é possível uma abordagem em ambas as direções, como gostaria de poder mostrar.

\section{Sobre as fontes}

O conhecimento das práticas de leitura literária faz parte, no interior do nosso grupo de pesquisa, dos maiores esforços de pesquisa que empreendemos, uma vez que só a partir daí é que se poderá propor novas e necessárias perspectivas de educação literária. A teoria nasce da observação da realidade e não o inverso. Assim, a pesquisa empírica mostra-se fundamental para conhecer as práticas escolares de leitura contemporâneas de alunos e de professores, o que nos permite propor reconfiguração de rumo e novas abordagens.

Para este estudo sobre a recepção do conto "Felicidade Clandestina", servimo-nos das seguintes fontes: relatos de professoras do Profletras (de 2015 a 2019) sobre a leitura do conto feita por seus alunos da educação básica quando discutido discutimos a recepção literária em uma aula de pós-graduação ${ }^{4}$; relatos de estudantes da disciplina de pós-graduação de 2019, ministrada por mim na FEUSP (Literatura e ensino na contemporaneidade), quando então apresentei o conto para discussão, tendo feito o

${ }^{4}$ Trata-se da disciplina Leitura do texto literário, ministrada de 2015 a 2019 por mim e por Vima Lia Rossi Martin, no programa do Profletras da FFLCH-USP. 
mesmo para alunos da disciplina de Metodologia do Ensino de Língua Portuguesa e da disciplina de Pedagogia, ambas da Faculdade de Educação da USP, ministradas em 2020 e online devido à pandemia. Colhi dados de leitura subjetiva e interpretativa de professores (no caso do Profletras e do curso de pós-graduação da FE) que já haviam trabalhado o texto com seus alunos do ensino básico e que puderam expor como isso transcorreu, bem como eles próprios puderam apresentar suas impressões de leitura pessoal e analítica do conto. Quanto aos alunos da Licenciatura e da Pedagogia (disciplina Texto e imagem: a literatura para crianças na escola) solicitei que apresentassem suas impressões de leitura, sem intenção analítica. Obter essas impressões não é algo fácil, pois no ensino básico esses alunos já fizeram um percurso de leitores a partir de um viés de expertise, o que em verdade se traduz por algumas tentativas de análise escolarizadas. No caso dos alunos de Letras, ainda que marcados pelos estudos críticos, houve empenho em refletir sobre o texto baseados numa leitura sensível, pessoal. Desse modo, discutindo com eles a perspectiva da leitura literária, pessoal e interpretativa, foi possível recolher considerações capazes de fornecer matéria importante para a reflexão que faço aqui. ${ }^{5}$

\section{Breves informaçồes sobre 0 conto}

Julgo que algumas linhas gerais do enredo são necessárias para a retomada que farei depois: o conto se centra na relação de duas meninas, provavelmente com 12 ou 13 anos, numa escola de Recife. A narradora, menina loira, apresenta-se, a si e a seu grupo de amigas, de um modo bastante altivo - "nós que éramos imperdoavelmente bonitinhas, esguias, altinhas, de cabelos livres" e "achatadas" -, enquanto a outra é rebaixada física e culturalmente pela narradora - "gorda, baixa, sardenta e de cabelos excessivamente crespos, meio arruivados. Tinha um busto enorme. Como

\footnotetext{
${ }^{5}$ Espero ter a oportunidade de desenvolver uma pesquisa de campo sistematizada e estruturada para obter resultados mais próximos de práticas reais de sala de aula visando à recepção na escola dos textos literários de Clarice Lispector, escritora que, pela característica da escrita, permite essas ressignificações de que nos ocupamos aqui. Destaco dois trabalhos que caminharam nesse sentido: a dissertação de mestrado (Profletras) de Ana Carolina Morais, Uma experiência de leitura literária no Ensino Fundamental II: A hora da estrela, de Clarice Lispector, defendida em 2018, e o artigo de Sarah V. Soares e Neide Rezende, "A leitura literária de a Hora da Estrela: um percurso de encontros e descobertas", revista Graphos, 2019.
} 
se não bastasse enchia os dois bolsos da blusa, por cima do busto"; tal personagem escrevia cartões de Natal com letra bordada com imagens e mensagens convencionais - era excluída das relações pela turma da narradora. Mas a menina ruiva "possuía o que qualquer criança devoradora de histórias gostaria de ter: um pai dono de livraria". O enredo se desenvolve com a menina loira tentando conseguir o livro Reinações de Narizinho que a menina ruiva prometeu emprestar, mas cuja entrega dificulta. Depois de muitas idas e vindas, a narradora-personagem consegue o livro mediante a intervenção da mãe da menina ruiva. Após ter em mãos o livro, adia a leitura, desfrutando do objeto e da antecipação do prazer de lê-lo, com uma lubricidade que lembra a do desejo sexual. O conto termina com a frase impactante e muito conhecida: "Não era mais uma menina com um livro: era uma mulher com o seu amante".

\section{A crônica "Tortura e Glória"}

Esse conto tem uma história que perpassa em parte a abordagem que se faz dele e que se imiscui no caminho interpretativo trazido muitas vezes pelos(as) professores(as) quando se conhece um pouco da história da sua autora: ser abordado como uma "narrativa autobiográfica".

Sua primeira publicação foi no Jornal do Brasil, com o título "Tortura e glória", em 02/09/1967, na coluna de crônica semanal que Clarice manteve de 1967 a 1973 (mais tarde, essas crônicas estarão reunidas no livro de crônicas Descoberta do mundo, publicado em 1984, sete anos após a morte da escritora). Em 1971, Clarice insere a crônica num livro de contos, com o título "Felicidade Clandestina", que também dá nome ao livro. Trata-se do mesmo texto, apenas tendo sido realizadas algumas poucas intervenções, como a subtração de alguns adjetivos, para a publicação do conto em 1971.

A narrativa refere-se a um fato ocorrido na vida de Clarice. Ao menos é assim claramente afirmado no depoimento de Suzana Rorovitz colhido por Nádia Battella Gotlib (1995) na biografia que escreveu sobre a escritora, Clarice. Uma vida que se conta. Segue um trecho desse depoimento: 
Quem conheceu melhor a Clarice foi minha irmã, Reveca. Sou mais ou menos cinco anos mais moça do que a minha irmã. Eu era menor e não tinha noção do grau de amizade delas. Saíam juntas. (...) Reveca, Clarice, as irmãs Lispector, uma prima que mora aqui, a Berta. Em uma turma só. [...] .

O que estava bem situado na época era meu pai, porque tinha uma livraria. Clarice não era uma menina de posse. E tinham de estudar. Clarice se sobressaía em português, já naquela época. Porque a minha irmã emprestava livros a ela. Livros de Machado de Assis, de Monteiro Lobato. Tínhamos uma biblioteca muito grande em casa. Um quarto da casa era só biblioteca. (...) E Clarice não tinha essas coisas. [...] O professor passou um trabalho para fazerem. Mas Clarice não tinha o livro. Então minha irmã prometeu a Clarice que emprestaria o livro para ela ler.

Um certo dia eu estava em casa quando Clarice chegou.

- A Reveca está?

- Ela não está.

- Ela me prometeu que deixaria o livro com a senhora.

E me lembro que ela começou a chorar.

- Venha no sábado que ela vai lhe emprestar.

No sábado ela foi, de manhã.

Clarice perguntou outra vez. Reveca não estava nem tinha deixado o livro. Minha mãe ficou muito aborrecida com a Reveca. Aí minha mãe pegou Clarice e disse para ela escolher tudo que ela quisesse.

- Leve os livros que você quiser. Leve!

Aí ela não teve dúvida. Pegou um monte de livros.

- E é a Reveca que vai ficar de castigo, disse a minha mãe.

Ela sabia que os pais de Clarice não tinham posse.

A Reveca chegou e ficou de castigo.

- E vai ficar sem os livros que precisava para os trabalhos - disse a minha mãe.

Reveca faleceu há mais ou menos vinte anos. Faleceu antes de Clarice. [...]

Diziam que Clarice tinha inveja de Reveca porque ela tinha boneca de louça suiça, borrachas importadas, lápis de cor, caderno de desenho, tinha tudo estrangeiro, que meu pai comprava. Depois desse caso dos livros, ela nunca mais veio em casa. Ela de- 
vorava os livros com os olhos. Acho que nunca tinha visto tanto livro dentro de uma casa.

Clarice soube no Rio que minha irmã tinha morrido. Disseram que ela escreveu uma crônica no JB muito bonita sobre Reveca. Disseram que depois ela reuniu num livro.

(GOTLIB, 1995, p. 99-100).

Não é difícil reconhecer que Reveca é a menina ruiva. Este trecho deixa ver que muito provavelmente a irmã de Reveca não havia lido a crônica no Jornal do Brasil e que parece mesmo ter sido ludibriada por quem lhe contou sobre isso, já que informa ser uma "crônica muito bonita", dando a impressão por suas palavras de que a considerava uma homenagem a Reveca. Mas o tom de Clarice para tratar do fato ocorrido não engana o leitor, por mais ingênuo que este seja: não é de homenagem que se trata, talvez, um registro da memória ou, mais provável, uma vingança. Agora a mulher adulta (a antiga menina loira) pode vingar-se da outra (a menina ruiva) contando, à sua maneira, o episódio da infância. Ela não tem uma livraria, mas possui o poder da escrita. A depoente (a irmã de Reveca) tomou conhecimento do texto no jornal mediado e mascarado por terceiros, como que edulcorado pela homenagem. No trecho da entrevista, lemos que a invejosa era Clarice e não Reveca.

\section{A passagem da crônica para o conto - ou da confissăo para a ficçăo}

As crônicas publicadas por Clarice com intermitência no Jornal do Brasil, ao longo de seis anos, possuem características muito pessoais, às vezes afastando-se, outras se aproximando do que convencionalmente se concebe como crônica: em muitas publicações, tratava-se de pensamentos, reflexões sobre si mesma, sem relacionar propriamente a um episódio ocorrido, como sói acontecer com o gênero crônica.

A própria escritora - numa crônica de 1968, época em que seu amigo Rubem Braga era a maior referência como cronista - revela sua resistência em adaptar-se a um modo de ser popularizado pela crônica de jornal, ao comparar seu modo de escrever em livro e em jornal: 
Mas mudar só porque isto é uma coluna ou uma crônica? Ser mais leve só porque o leitor assim o quer? Divertir? Fazer passar uns minutos de leitura? E outra coisa: nos meus livros quero profundamente a comunicação profunda comigo e com o leitor. Aqui no jornal apenas falo com o leitor e agrada-me que ele fique agradado. Vou dizer a verdade: não estou contente. $\mathrm{E}$ acho mesmo que vou ter uma conversa com Rubem Braga porque sozinha não consegui entender (SER CRONISTA, 22/06/1968. Descoberta do Mundo, p. 113).

No mesmo texto, manifesta o medo de se tornar "pessoal demais, correndo o risco daqui em breve de publicar minha vida passada e presente, o que não pretendo". Enquanto leitora dessas crônicas, tenho a impressão de me aproximar da verdadeira Clarice, de conhecê-la melhor enquanto pessoa, conhecer sua vida social, doméstica e familiar, conhecer as empregadas da casa e os encontros casuais com gente de todo tipo na rua, a circulação nos meios das celebridades intelectuais e o convívio amigável e afetuoso com elas. Desse modo, ao ler as crônicas reunidas no livro $A$ descoberta do mundo, a enigmática autora de literatura Clarice Lispector se torna uma pessoa mais comum e próxima, tão confessionais são às vezes seus textos.

Ao ser publicado em 1971, no livro de contos, o texto "Tortura e glória" muda então de gênero e, como dito, recebe o título de "Felicidade Clandestina" - o que evidentemente interfere na apreensão e na trajetória interpretativa do conto ao longo do tempo.

Ao receber o estatuto de "conto", o texto ganha autonomia em relação à vida particular da autora e transfere-se para o plano ficcional, mudando seu estatuto enquanto gênero e, portanto, conferindo outra natureza ao texto. Como pontua Ricardo lannace (2001, p. 49), "se antes a protagonista estava sob o domínio da filha do livreiro, agora, na posição de narradora, exerce pleno controle sobre o leitor", como também o exerce sobre a matéria narrada, transformando-a em experiência que transcende o cotidiano e se desvencilha da situação real - ou seja, enquanto literatura, não reflete $o$ real e sim reflete sobre o real. "Os sinais da ficcionalidade também põem entre parênteses o mundo apresentado pelo texto, indicando ao mesmo tempo que esse mundo que não só deve ser visto como tal, mas também entendido como mundo que não existe empiricamente." (ISER, 2013, p. 301). 
Se o leitor não conhece o histórico do texto, é levado a se desprender da ocorrência na vida pessoal da autora, mas ainda assim pode ler o conto mantendo resíduos de sua autobiografia, uma vez que - na escola, pelo menos - é de praxe garantir ao aluno, antes da leitura, informações factuais sobre o autor e a obra. Ora, pensa o leitor, uma grande escritora como Clarice Lispector só poderia mesmo ser uma leitora apaixonada, ser aquela menina loira, culta e sensível torturada pela ruiva inculta e grosseira. Sem dúvida este é um forte viés de leitura quando se aceita a perspectiva da narradora, fazendo vista grossa para a sua autoironia.

Estaria bem próximo da realidade afirmar que do conto de Clarice é essa a interpretação que perdura na trajetória percorrida desde seu lançamento até hoje: nas palavras de professores, alunos, nos sites, nos materiais didáticos... "As avaliações das obras refletem certas atitudes e normas do público contemporâneo, de modo que à luz da literatura se manifesta o código cultural que orienta tais juízos" (ISER, 1996, v. 1, p. 64).

Entretanto, a força de uma reconhecida obra literária, um cânone, se situa em geral no seu potencial polifônico, na capacidade de comunicar-se com diferentes gerações de leitores e atualizar-se em cada leitura, "a noção de cânone guarda relação com a transitoriedade, com a época e sua fugacidade, mas, também, com a permanência" (FREDERICO; OSAKABE, 2004, s/p).

\section{0 conto Felicidade Clandestina na escola: idealizaçầo do leitor}

Presente o conto na escola ao longo das décadas, popularizado pelos livros didáticos, que também se multiplicaram a partir da década de 1970, supõe-se ter sido e ainda ser muito lido na sala de aula, a exemplo de outros textos de Clarice que tematizam o universo da adolescência e a lubricidade que vigora nessa etapa da vida, a qual em geral vem oculta nos textos da escritora pelas metáforas ou alegorias.

A "paixão pela leitura", associada à personagem da narradora em oposição à da menina que tinha o livro mas não o lia tornou-se a principal entrada no conto: "'Felicidade Clandestina' é uma narrativa sobre o prazer da leitura", lê-se em sites de hoje. E quem de nós, professoras de Português, não leu o conto impactadas pelo encantamento da menina diante da posse de Reinações de Narizinho? 
Ainda que convencionalmente se considere a "identificação" como elemento negativo de leitura das obras na escola, em razão de não permitir o distanciamento crítico necessário para o trabalho com a literatura, persiste a adesão a essa personagem, associada à autora Clarice Lispector, como abordagem essencial do conto, sobretudo por parte dos professores(as) - é o que colho nos relatos, fontes deste artigo. Não se trata de nenhum despropósito essa associação entre as diferentes instâncias, uma vez que se torna difícil dissociar "entre a voz da consciência que narra, a personagem que é narrada por si mesma e a escritora Clarice Lispector" (ROSENBAUM, 2006, p. 72).

O conto parece propor um ideal de leitor, que se coaduna com uma vertente de formação, considerada fundamental para a formação do sujeito, e que se pode chamar de "ideal humanista":

\footnotetext{
uma representação escolar da literatura que considera que esta constitui uma espécie de fato cultural total, encarregada de preencher todas as funções possíveis e imagináveis ligadas à formação e à informação da pessoa: despertar intelectual e educação sentimental, formação moral e formação estética, solidão interior e comunicação com seres defuntos ou imaginários, informação sobre o mundo e sobre os outros, conhecimento científico e edificação religiosa etc. O livro seria nesse espírito a fonte de todos os conhecimentos, de todas as experiências e de todos os divertimentos. (BAUDELOT, CARTIER, DETREZ, 1999, p. 246).
}

O livro que a menina está desejando, Reinações de Narizinho, parece funcionar como um fetiche, que amalgama essa idealização. Publicado em 1931 (essa menina narradora/Clarice deve tê-lo lido em 1932) representava um grande momento para Monteiro Lobato que aparecia como um escritor fabuloso de literatura para crianças. Sua Narizinho era naquele livro a "rainha delicada" do reino e da identificação da menina loira.

Essa idealização da leitora apaixonada encontra respaldo em estudos críticos sobre a autora, como em "O olhar do mal" de Yudith Rosenbaum, que conclui assim sua interpretação do conto (e que contribuirá para desenvolver a discussão a seguir): 
O conto, portanto, instaura duas atmosferas oponentes: a primeira, que se intensifica no segundo segmento, apresenta a virulência das relações humanas no jogo sádico da invejosa com a voraz leitora; o mundo então surge desencantado e cruel, repleto de obstáculos e humilhações. A segunda parte transforma a degradação pérfida em momento epifânico, dominado pela suspensão das leis da realidade, onde o grotesco é abruptamente expurgado do texto, cedendo lugar de forma absoluta ao sublime erótico e estético. Eros, por fim, toma a palavra. Flagrante prova de amor à arte, acima de todo o infortúnio (ROSENBAUM, 2006, p. 82, destaque meu).

\section{A recepçầo de "Felicidade Clandestina" e o leitor implícito da década de 1970}

A cultura escolar até hoje não só se ocupou com o cânone, como também se ocupou em canonizar, no sentido de tornar os conteúdos "verdades", ao deixar de lado a instabilidade na organização discursiva, principalmente no que se refere ao livro didático, o que se transfere também para o discurso do professor, uma vez que, estando no mais das vezes, distante dos trabalhos científicos, são levados a adotar a perspectiva desses manuais ${ }^{6}$.

Por mais que o tempo mude os leitores, por mais que saibamos que cada sentido atribuído aos textos varie - entre leitores e mesmo entre leituras de um mesmo leitor - e que os valores de uma sociedade mudem com o tempo, que as pesquisas acadêmicas revisitem as obras e atribuam-lhe novas interpretações, há uma tendência na cultura escolar de reter determinados conteúdos e abordagens como se fossem naturais e próprios da escola. Essa leitora que se mostra em "Felicidade Clandestina" é tão sublime que mesmo pessoas autoconsideradas grandes leitoras não se reconhecem nela, como confessou uma professora universitária, hoje com 50 anos, que, tendo lido o livro na adolescência, angustiava-se por não conseguir se ver naquela leitora do conto, ela, grande leitora de literatura, filha de intelectuais, boa aluna de um bom colégio burguês.

6 "Pensa-se como verdades afirmações que, naturalizadas pelos discursos, no caso aqui pelos discursos sobre a literatura, são dadas como óbvias e verdadeiras. Funcionando como chaves de interpretação, elas passam a dispensar uma investigação mais apurada do objeto de análise, acabando por explicá-lo por meio de ideias e noções já previamente determinadas e fixadas." (LIMA, no prelo). 
O texto se estrutura em torno desse tipo de leitor especialíssimo, conveniente, de resto, para a escola, já que esta tem a função de formar seus alunos como leitores; assim, fixa-se com propriedade o discurso sobre o "prazer da leitura" provindo de uma fala irretocável, a "verdade" de uma grande escritora. Sem esquecer que essa imagem idealizada de leitora se coaduna com uma personagem de aspecto burguês, branca, loira, elegante, contrapondo-a à outra desmerecida fisicamente, tornando-a repulsiva, apresentando o corpo grotesco como metáfora da moral. Não que a construção dessa disparidade não fosse sendo tecida de modo provocativo, como para explicitar ironicamente para o leitor que a construção do contraste tampouco era destituída de consciente crueldade "nós que éramos imperdoavelmente bonitinhas, esguias, altinhas, de cabelos livres". Também se percebe na autoimagem aquele tantinho de autocomiseração, nas olheiras do sofrimento autoimposto, na compaixão entrevista na atitude da mãe da menina "má"...

\section{De narradora vítima $x$ antagonista algoz a narradora algoz $x$ antagonista vítima}

Assim, a narrativa, ao mesmo tempo em que constrói uma perspectiva positiva da narradora, também constrói sua face perversa: "A narradora também se coloca aqui em posição muito pouco inocente, submetendo a colega a um olhar humilhante, de quem detém uma imagem tão superior de si mesma que a defasagem qualitativa entre ambas se torna inevitável aos olhos do leitor" (ROSENBAUM, p. 75).

Ora, segundo alguns/as dos(as) nossos/as informantes, quando feita a leitura do conto, essa arrogância da narradora é o que se destaca, e surgem comentários como: "isso é bullying!", "metidinha", e até mesmo "racista" por causa da referência a Lobato. Ou seja, na escola de hoje, com os alunos de hoje, em especial na escola pública de hoje - com a diversidade econômica, cultural e étnica, sobretudo a predominância de alunos de cor não-branca - com a consciência agressiva de suas identidades, na leitura do conto a posição da narradora não é mais passível de enaltecimento, apreende-se antes o viés da arrogância e da discriminação. 
Ou seja, se levados a ler efetivamente a obra e se lhes é dada a oportunidade de manifestar-se é provável que esta e outras posições possam surgir, como abordagens das comunidades interpretativas, que adquirem particularidades nos lugares em que se formam - por exemplo, os movimentos de escritores de periferias, os coletivos teatrais, os festivais de SLAM, as redes sociais e sua imensa variedade de agrupamentos e conteúdos são eventos que, muitas vezes invisíveis para os professores, formam e firmam posições que atuam na percepção da cultura escolar.

Dependendo das condições históricas da leitura, da cultura e do lugar, o leitor pode se ater a uma interpretação ou a outra. Assim como a produção da obra responde a um horizonte sociocultural, que pode confirmar ou, ao contrário, transgredir as expectativas de uma época, também a recepção da obra se encontra dentro dos contornos desse universo de época.

Outro distanciamento em relação à narradora está no fato de ser ela a leitora apaixonada, com o que os estudantes tampouco se identificam. Em pesquisas de campo sobre leitura literária realizadas na pós-graduação junto a alunos de escolas públicas, quando perguntados se se consideram leitores, geralmente respondem que não ${ }^{7}$. Tanto estudantes do Ensino Fundamental quanto do Ensino Médio indicam suas práticas rarefeitas de leitura, que se mesclam no meio digital a outros universos semióticos. Não se identificam com aquela mocinha branca e burguesa que lhes é apresentada, e provavelmente não se sentem angustiados como aquela adolescente dos anos 80 que não se via na grande leitora de Clarice, porque introjetam uma outra identidade sociocultural.

\section{A leitora de Lobato e o polêmico Lobato de hoje}

Essa imagem de positividade da leitora do conto se manteve ao lado do engrandecimento de Lobato, que, desde as primeiras publicações das personagens do Sítio do Picapau Amarelo, na década de 20, era reverenciado como o criador da literatura infantil de alta qualidade e em 1971, permanecia o grande escri-

${ }^{7}$ Também a pesquisa de amplo espectro Retratos da Leitura no Brasil corrobora a pouca leitura de livros por estudantes em idade escolar. Entretanto, o que mais importa aqui é a imagem de leitores que fazem de si mesmos, assim como, usuários da língua, muitas vezes dizem não conhecer a língua portuguesa. 
tor para crianças, onipresente na escola ${ }^{8}$, e Clarice se tornava a grande escritora enigmática, voltada para uma camada de leitores mais instruídos e proficientes (mais burgueses?).

Neste início de século XXI, Lobato é um escritor polêmico. Não quero entrar nos meandros da polêmica, mas o certo é que a acusação de referências racistas em sua obra atingiu em cheio a escola, cujos estudantes se mostram atentos às manifestações de discriminação - muito mais que no início da década de 70 , quando a escola pública recebia quase que exclusivamente alunos brancos $^{9}$. Portanto, os alunos não estão infensos a essa visão negativa de Lobato, que também desliza para a leitura de "Felicidade Clandestina", ainda que Reinações de Narizinho, a meu ver - no trecho em que Narizinho apresenta Tia Anástácia ao público do Reino das Águas Claras -, revele mais bem uma astúcia de Lobato ao transferir o preconceito ao público e expor a artimanha de $\mathrm{Na}$ rizinho para contornar a questão ${ }^{10}$. Por outro lado, revela a condição histórica do negro, após a abolição, quando logo no parágrafo inicial denomina Tia Anastácia como "negra de estimação".

Ora, nesse conto extraordinário, o leitor implícito que Clarice constrói abre brecha também para essa leitura. As ambiguidades e reposicionamentos que a autora vai tecendo ao longo do texto aceitam vieses interpretativos diversos e evitam canonizar apenas a da boa menina leitora, vislumbrando-se seu desejo de vingança e sua presunção, aspecto que em determinado momento da vida cultural e social pôde se sobrepor a determinadas comunidades leitoras.

\footnotetext{
${ }^{8}$ Eu mesma, aluna de escola pública nos anos 60, fui leitora assídua de Lobato, e me lembro dos trabalhos sobre os seus livros que eram solicitados no ginásio (EF II). Nem se cogitava ainda sobre as questões de racismo ou de danos ao meio-ambiente, que hoje estão na pauta na crítica a Lobato. A dissertação de Filipe Rodrigues dos Santos, $O$ controle da recepção de obras literárias na escola: o caso de Monteiro Lobato (FEUSP, 2020), aborda o tema a partir da polêmica de 2010 sobre Caçadas de Pedrinho. O assunto específico do entrevero foi a abordagem presumivelmente racista de Tia Anastácia, mas no episódio do Sítio encontra-se também a agravante da matança da onça, que hoje é inadmissível diante da consciência e das políticas de preservação dos animais e da floresta.

9 Um exame de admissão, só extinto oficialmente em 1972, selecionava a entrada para o ginásio (EFII). Quando, a partir de então a escola se abriu para todos, a arquitetura dos prédios também se transformou. Novas construções mais precárias, em seguida gradeadas, e as tristemente famosas "escolas de lata", surgiram nos anos 80

${ }^{10}$ No trecho, Pedrinho avisa que talvez Tia Anastácia não venha. "Está com vergonha, coitada, por ser preta". Ao que Narizinho respondeu "Que não seja boba e venha (...) eu dou uma explicação ao respeitável público". No início do espetáculo, apresenta assim Tia Anastácia: "Não reparem ser preta. É preta só por fora, e não de nascença. Foi uma fada que um dia a pretejou, condenando-a a ficar assim até que um dia encontre um certo anel na barriga de um certo peixe. Quando o encanto se quebrará e ela virará uma linda princesa loura". Assim está escrito na 2a. edição de 1981, da editora Brasiliense, no 5․ episódio, "O Espetáculo", p. 161. Entretanto nem todas as edições trazem o trecho ou o trazem assim.
} 
"Felicidade clandestina" se desvencilha da situação real e ganha plenos poderes em relação à matéria, mas deixa latente a inveja e a vingança (que remetem à outra) e vai construindo para o leitor uma menina aparentemente sedutora, que é a menina leitora, sem deixar, contudo, de oferecer indícios de sua própria crueldade.

E o fato de a narradora fazer referência a Lobato não deixa de ser um discurso sobre a recepção dentro do conto. A remissão a um dado histórico que deslocaria o texto para fora da ficção, talvez aproximando-o ainda mais da autobiografia, nesta situação produz um efeito em espiral, mostrando que a realidade e a memória pessoais importam menos que as obras. Estas, sim, devem ser perenes e isso é o que faz ao imortalizar Lobato, mostrando que a literatura funciona assim mesmo: objeto de prazer e desejo de um certo tipo de menina e rejeitado por outro. Nesse sentido ainda, Clarice liberta os leitores, mostrando que não precisam gostar nem do ela lê nem do que ela escreve e nessa indiferença exerce outra instância de sua crueldade: pode-se gostar ou não, pode-se compreender ou não, basta aceitar a identificação com os que leem ou com os que não leem.

Esses posicionamentos exigem do professor que ele reflita sobre essas potencialidades da literatura, que ele se permita uma mudança de percepção acerca das leituras sacralizadas e idealizadas que se repetem muitas vezes no universo escolar. Uma mediação que vá além da identificação com as personagens, mas que também as leve em conta. De fato, é necessário repensar a busca de sentido no trabalho com o texto literário e tratar essa busca como um jogo entre diferentes leitores que pelo diálogo compartilham os múltiplos significados sobre o texto como objeto a ser compreendido e interpretado. Se uma primeira aproximação pode passar pela identificação ou rejeição às personagens, é fundamental que o professor conduza o jogo no sentido da imersão no contexto literário que pressupõe um exercício de simulação, um "faz de conta que" fundamental à dramatização do si mesmo frente à realidade do texto; sem dúvida, aprendizagem indispensável que a literatura propicia quase que exclusivamente.

Termino com uma das frases de uma aluna da Pedagogia no seu comentário do conto: "Contudo, a ideia da felicidade clandestina proposta parece ser atemporal e universal, uma vez que os objetos da alegria e do desejo podem ser múltiplos e sempre 
haverá algo cerceado ou inacessível ao indivíduo que possibilitará esta felicidade caso obtido".

\section{Referências}

BAUDELOT, C.; CARTIER, M.; DETREZ, C. Et pourtant ils lisent... Paris: Seuil, 1999.

FREDERICO, E. Y.; OSAKABE, H. "Literatura". Introdução. In: BRASIL, Ministério da Educação. Brasília: SEB, 2004. Disponível em http://portal.mec.gov.br/seb/ arquivos/pdf/03Literatura.pdf. Acesso em 28 fev.2021.

GOTLIB, N.G. Clarice. Uma vida que se conta. São Paulo: Ática, 1995.

IANNACE, R. A leitora Clarice Lispector. São Paulo: EDUSP, 2001.

ISER, W. $\mathbf{O}$ ato da leitura. Teoria do efeito estético. Tradução de Johannes Kretschner. São Paulo: E. 34, 1996. V. 1.

ISER, W. $\mathbf{O}$ ato de leitura. Teoria do efeito estético. Tradução Johannes Kretschmer. São Paulo: Ed. 34, 1996. Cap. 2 - Reflexões preliminares para uma teoria do efeito estético. V. 2

ISER, W. O fictício e o imaginário: perspectivas de uma Antropologia literária. Tradução de Johannes Kretschmer. Rio de Janeiro: EDUERJ, 2013.

JAUSS, H.R. A história da literatura como provocação à teoria literária. São Paulo: Ática, 1994.

LIMA, C. Y. P. , "Sobre o conceito de literatura nos livros didáticos: uma perspectiva a partir da análise do discurso". In: REZENDE, N., OLIVEIRA, G. R., SOUZA, M. C., Literatura e ensino: pesquisa e constituição de um campo. São Paulo: Alameda, no prelo.

LISPECTOR, Clarice. "Tortura e Glória”. In: LISPECTOR C. A descoberta do mundo. Rio de Janeiro: Rocco, 1999.

LISPECTOR, Clarice. Felicidade Clandestina. In: LISPECTOR, C. Todos os contos. Rio de Janeiro: Rocco, 2016.

ROSENBAUM, Y. "Olhar do mal". In: ROSENBAUM, Y. Metamorfoses do Mal: uma leitura de Clarice Lispector. São Paulo: EDUSP, 2006.

SANTOS, F. R. O controle da recepção de obras literárias na escola: o caso de Monteiro Lobato (Mestrado em Educação). FEUSP, 2020. 